\title{
Overview: Documentation and monitoring of landslides and debris flows for mathematical modelling and design of mitigation measures - outcomes of the EGU 2011, NH session
}

\author{
L. Franzi ${ }^{1}$, M. Arattano ${ }^{2}$, M. Arai ${ }^{3}$, and O. Katz ${ }^{4}$ \\ ${ }^{1}$ Regione Piemonte, Soil defence department, Via Petrarca, 44 - 10126 Torino, Italy \\ ${ }^{2}$ CNR-IRPI, Strada delle Cacce, 73 - 10135 Torino, Italy \\ ${ }^{3}$ Mejo University, Department of civil engineering, 1-501 Shiogamaguchi, Tempaku-ku, Nagoya, 468-8502, Japan \\ ${ }^{4}$ Geological Survey of Israel, Engineering Geology and Geological Hazards, 30 Malkhe Israel St., Jerusalem 95501, Israel \\ Correspondence to: L. Franzi (luca.franzi@regione.piemonte.it)
}

\begin{abstract}
The papers summarised in this paper represent the scientific contributions of several scientists, coming from different countries, who work in the fields of monitoring, modelling, mapping and design of mitigation measures against mass movements. The authors participated at the 2011 EGU General Assembly presenting the contributions summarised in this paper. At the General Assembly they had the opportunity to illustrate their recent advancements, discuss each other's needs and set forth future research requirements. The scientific contributions presented here can be considered the result of the debates and the exchanges regarding their original work presented at the General Assembly that occurred either personally during the open session or during the review phase of their manuscripts.
\end{abstract}

\section{Introduction}

The special issue "Documentation and monitoring of landslides and debris flows for mathematical modelling and design of mitigation measures" of the journal Natural Hazards and Earth System Sciences of the European Geosciences Union gathers some of the contributions proposed at the homonymous open session that was held during the EGU General Assembly 2011 (http://meetings.copernicus. org/egu2011/).

The session offered to scientists working in the same field of research a chance to interact with each other in a scientific contest. Among the overall 22 presentations submitted for the session, 14 were proposed for this special issue and 11 were finally accepted. In the following we will summarise the content and the main results of the 11 published papers.

The themes of the different contributions range from pure theoretical investigations to laboratory experiments and in situ investigations. Three main groups of papers have been formed. The first group deals with theoretical investigations, flume experiments, laboratory and mathematical tests. The second group contains papers dealing with documentation in specific instrumented areas. In the third group, papers can be found that deal with hazard assessment in large watershed basins, where either traditional or innovative means of analysis have been proposed by the authors.

\section{From laboratory experiments to mathematical tests}

A considerable part of the special issue is dedicated to laboratory experiments, tests and theoretical research (4 papers out of 11). Fang et al. (2012) are among the latter and investigate the formation process of rainfall-induced landslides that occur on slopes composed of loose soil in the Wenchuan earthquake region. Their research lies at the border between laboratory-theoretical experimentation and applied research. Some experimental investigations have been performed by the authors on the landslide soil samples taken from Weijiagou gully, which is frequently affected by debris flow. The variation of the controlling soil parameters (water content, pore pressure, etc.) under various artificial rainfall conditions has been tested during the experiments. The laboratory equipment was composed by a test flume, an artificial rainfall system and some sensors, with the aim of measuring the variation of internal soil parameters, including the water content 
and the pore water pressure. The tests showed the role played by the accumulation of fine particles, which cause a decrease of the water infiltration in the soil and enhance the probability of the debris-flow occurrence. According to the evidence of the tests, the authors claim that it is probably the accumulation of fine particles to induce a sharp increase in water content and pore water pressure, with consequent occurrence of debris flows in the Wenchuan region. Their tests are performed in very simple conditions, i.e. by assuming an infinite slope with constant soil thickness. When the geometry is not simple and the inertial terms of the process are more relevant, laboratory tests show to be the most effective means of research.

The paper by Canelli et al. (2012) presents the results of some experimental tests, carried out through a specific flume, to obtain a detailed knowledge of the mechanical aspects of a debris flow impacting on different types of structures, and to analyze its dynamics. The authors have calculated the thrust caused by the flow and have analyzed the dynamics of the impact, which has shown differing effects according to the type of barrier employed. According to the authors, the debris-flow thrust on rigid barriers can be estimated using the equilibrium of the quantity of motion, corrected with a suitable safety factor. The latter is needed to take into account the possibility of the formation of a vertical jet-like wave after the impact that would lead to an underestimation of the design thrust value. According to the authors, during the design phase, the type of flow should be correlated to the type of barrier installed (rigid or filtering) and to the possibility of applying a homogeneous fluid scheme. The impact of masses of large dimensions could in fact generate impulsive forces on the barrier much higher than those estimated utilizing an equivalent fluid scheme. Deformable barriers would allow a reduction of the impulsive effects of these masses.

An example of research in which experimental data and theoretical results are compared is represented in the paper by Hotta (2012). The research carried out by the author is focused on the measurement of the interstitial water pressure of debris flows under various conditions, during debris-flow routing experiments in a laboratory flume. According to the author, the data allow to obtain essential information on the flow stress structure. Because a sensitive pressure gauge is required to measure the interstitial water pressure in shallow laboratory debris flows, a differential gas pressure gauge with an attached diaphragm was used during the experiments. Although this system required calibration before and after each experiment, it showed a linear behaviour and a sufficiently high temporal resolution for measuring the interstitial water pressure of debris flows. The data show an excess of pressure beyond the hydrostatic pressure that was observed with increasing sediment particle size. The measured excess pressure corresponded to the theoretical excess interstitial water pressure, derived as a Reynolds stress in the interstitial water of bouldery debris flows. The study may shed some light on the effect of the changes in the interstitial water pressure during debris flows, on turbulence effects, and on the transition phase from laminar to turbulent debris flows.

A good example of mathematical modelling of complex systems is given by Tai et al. (2012), who focus their research on a saturated binary mixture model for debris flows of the Coulomb-mixture type, over a temporally varying topography. In the model both the effects of erosion and deposition are considered. The authors observe that, due to the deposition or erosion processes, the interface between the moving material and the stagnant base is a non-material singular surface. Therefore, the model simulates the motion of this singular surface by considering the mass exchange between the flowing layer and the ground. In the study, a depth-integrated equation system with deforming coordinates for a Coulombmixture over general topography of small curvatures is introduced. Results are remarkable, expecially due to the complex system of equations that are solved; therefore, the authors call for future study and improvement.

\section{Documentation in specific areas}

The paper by Arattano et al. (2012) describes the dynamics of a debris flow occurred in one of the most studied and instrumented watershed basins in Italy: the Moscardo torrent, a basin of the eastern Italian Alps instrumented for debrisflow monitoring. Many researches have been already carried out in the same site, and other papers have been already published on different subjects, from rheology, to modelling and to instrumentation. The paper is about a debris flow that took place on 24 August 2006. The debris flow was recorded by two seismic networks. The authors point out that, in spite of the fact that a typical debris-flow wave was observed at the upper seismic network, with a main front abruptly appearing in the torrent, followed by a gradual decrease of flow height, the upstream observations were not confirmed by what happened on the debris fan. Actually, on the alluvial fan the wave displayed an irregular pattern, with low flow depth and the main peak occurring in the central part of the surge both in the seismic recording and in the hydrographs. The evidence collected on the debris fan showed that the wave probably consisted in a water surge laden with fine to medium-sized sediment. This induced the authors to give a different interpretation of the whole process: it was probably a debris wave that originated in the upper part of the basin, and, due to the attenuation of the surge caused by the torrent control works implemented in the lower basin during the last years, strongly changed its dynamics. The results show once more that, for the same watershed basin, the dynamics of debris flows can strongly change from one case to another and, in the same event, can significantly vary along the torrent.

The availability of reliable instrumentation systems is one of the most critical points for field research. On this subject, in the paper by Occhiena et al. (2012) a monitoring system is described in detail that is installed at the Carrel 
hut (3829 m a.s.l., Matterhorn, NW Alps) and is composed of geophones and thermometers. The installation aims at investigating the processes related to the permafrost degradation, which is a probable cause for the increase of rock instabilities and rock falls observed in recent years in high mountain areas, particularly in the Alpine region. The phenomenon causes the thaw of the ice filling rock discontinuities; the water deriving from it subsequently freezes again inducing stresses in the rock mass that may lead, in the long-term, to rock falls. In the paper, the data recorded by the monitoring system between 6 October 2010 and 5 October 2011 are presented and 329 selected microseismic events are analysed. The data processing has concerned the classification of the recorded signals, the analysis of their distribution in time and the identification of the most important trace characteristics in time and frequency domain. The interpretation of the results has evidenced a possible correlation between the temperature trend and the event occurrence. The research is still in progress and the data recording and interpretation are planned for a longer period to better investigate the spatialtemporal distribution of microseismic activity in the rock mass, with specific attention to the relation of microseismic activity with temperatures.

\section{Hazard assessment in watershed basins}

With respect to the complex monitoring systems described in the precedent section, more heuristic methods are generally proposed to model landslides susceptibility in debrisflow risk management, as it is described in the paper by Li et al. (2012). The approach is GIS based and relies on the backpropagation Artificial Neural Network model (ANN). The methodology has been applied to landslides that occurred in the Wenchuan region, which were triggered by two superposing factors, i.e. rainfalls and earthquakes. The landslides have been classified in a landslide inventory, derived from field investigation and aerial photo interpretation, according to the following classification criteria: 473 landslides (occurred before the Wenchuan earthquake) were considered as rainfall-induced landslides (RIL), and 885 were assumed to be earthquake-induced landslides. To understand the different impacts of rainfalls and earthquakes on landslide occurrence, the relationship between the landslide spatial distribution and the conditioning factors have been evaluated. The ANN structure and the factors combination have been changed by the authors in order to test how the conditioning factors had to be weighted to fit the data. The optimum combination and weight of the factors have been used to produce landslide susceptibility maps over the region. The model is of the black-box type, does not consider all the influencing triggering factors, but has the merit (1) to be based on data that can be easily obtained, and (2) to be used for estimating susceptibility in large areas. The neural network scheme allows the calibration of the model, for specific areas, and it is undoubtedly useful for risk assessment procedures in endangered regions.

The integrated method for predicting soil erosion and shallow landslide sediment yield, proposed by Hsu et al. (2012) is based on the HSPF and TRIGRS models and on the FLO2D model for calculating debris-flow sediment yield. The proposed method is applied to potential debris-flow watersheds located in the Sioulin Township of Hualien County. The method, has been successfully applied to 26 debris-flowprone creeks and demonstrates an ability to simulate the spatial distribution of shallow landslide and sediment yields associated with different transport mechanisms (such as fluvial transport and debris-flow scenarios). The method can be used to explore various scenarios, from shallow landslides, to debris flows. However the model needs the calibration of a huge amount of parameters (i.e. HSPF involves ten parameters), an operation that is not always simple to be done, especially when the data are scarce or poor. The strength in this approach is that the authors, in spite of the complexity of the three models which were used in the simulation, try to simplify the approach and to find a regression formula useful for practical applications. Therefore, the detailed approaches of HSPF TRIGRS and flow 2-D model are simplified, even to simple algebraic formulas, linking sediment yield to the watershed area.

In general, 2-D mathematical models are the most used methods for debris-flows hazard zone delineation, as shown by the paper by Tsai et al. (2012). The case study shown by Tsai et al. (2012) at Daniao tribe is a rare case where the computed hazard zoning has been performed well before the occurrence of the event. This has allowed it to be compare to a real case debris flow. Generally, only a back analysis is presented, i.e. an analysis of a debris-flow disaster after its occurrence. The most difficult tasks, in these simulations, are represented by the calibration of the involved parameters (rheology of the debris flow) and by the choice of the input variables (in particular the total volume of the debris flow). According to the results obtained by the application of the 2-D model, the predicted endangered areas match quite well with the real case. Moreover the application of the model shows the relative insensitivity of the results to the volume estimation. This is one important reason for its successful prediction. The case study of the Daniao tribe debris flow provides support for the usability of numerical simulations in real engineering detailed designs.

The paper by Lo et al. (2012) shows how different kinds of information and data should be gathered and implemented to allow a global understanding of the debris flows processes, and facilitate decision making. The paper analyses the way in which DTMs, field surveys and rainfall data can be used for the study of debris -low occurrence factors in the Shenmu area, Taiwan. The authors focus their investigation on the factors which are considered to be the most relevant in debrisflow disasters in the catchment areas around the Tsushui river and the Aiyuzih river. These factors are rainfall, geologic 
conditions and topography. The approach is very simple and tries to establish a connection between the three major factors that trigger debris flows in the Shenmu area. In particular, the authors compare the DTMs obtained by LIDAR surveys in different times. In this way they can easily identify the places where the debris flows initiate, flow and deposit in the basins watersheds. The results are very promising, as they are based on a quantitative comparison of digital terrain maps, and do not rely on subjective data interpretation. By means of the methodology discussed in the paper, the authors try to analyse the effects of the 2009 Morakot typhoon and of other antecedent intense typhoons occurred in the region.

An analysis of the rainfall conditions that affect debris flow triggering has been performed by Floris et al. (2012). The authors show the results of the application of a processbased model to define an hydrological alert system for the Val di Maso Landslide, which is located in the Vicenza Province (Veneto region, NE Italy), on the northeastern Italian Alps. Empirical and physically based models have been used by Floris et al. (2012) to identify the minimum rainfall threshold for the occurrence of instability phenomena in the crown area of the Val di Maso landslide. Empirical models helped in the identification and in the evaluation of the recurrence of critical rainfall events, while physically based modelling was essential to verify the effects of rainfall on slope stability. Combining results from empirical and physically based modelling, an alert threshold was found for a reactivation of the phenomenon. The proposed hydrological alert system can be applied to different scales of investigation and to different geological and geomorphological contexts.

\section{References}

Arattano, M., Marchi, L., and Cavalli, M.: Analysis of debrisflow recordings in an instrumented basin: confirmations and new findings, Nat. Hazards Earth Syst. Sci., 12, 679-686, doi:10.5194/nhess-12-679-2012, 2012.

Canelli, L., Ferrero, A. M., Migliazza, M., and Segalini, A.: Debris flow risk mitigation by the means of rigid and flexible barriers experimental tests and impact analysis, Nat. Hazards Earth Syst. Sci., 12, 1693-1699, doi:10.5194/nhess-12-1693-2012, 2012.

Fang, H., Cui, P., Pei, L. Z., and Zhou, X. J.: Model testing on rainfall-induced landslide of loose soil in Wenchuan earthquake region, Nat. Hazards Earth Syst. Sci., 12, 527-533, doi:10.5194/nhess-12-527-2012, 2012.

Floris, M., D’Alpaos, A., De Agostini, A., Stevan, G., Tessari, G., and Genevois, R.: A process-based model for the definition of hydrological alert systems in landslide risk mitigation, Nat. Hazards Earth Syst. Sci., 12, 3343-3357, doi:10.5194/nhess-123343-2012, 2012.

Hotta, N.: Basal interstitial water pressure in laboratory debris flows over a rigid bed in an open channel, Nat. Hazards Earth Syst. Sci., 12, 2499-2505, doi:10.5194/nhess-12-2499-2012, 2012.

Hsu, S. M., Wen, H. Y., Chen, N. C., Hsu, S. Y., and Chi, S. Y.: Using an integrated method to estimate watershed sediment yield during heavy rain period: a case study in Hualien County, Taiwan, Nat. Hazards Earth Syst. Sci., 12, 1949-1960, doi:10.5194/nhess-12-1949-2012, 2012.

Li, Y., Chen, G., Tang, C., Zhou, G., and Zheng, L.: Rainfall and earthquake-induced landslide susceptibility assessment using GIS and Artificial Neural Network, Nat. Hazards Earth Syst. Sci., 12, 2719-2729, doi:10.5194/nhess-12-2719-2012, 2012.

Lo, W.-C., Lin, B.-S., Ho, H.-C., Keck, J., Yin, H.-Y., and Shan, H.-Y.: A simple and feasible process for using multi-stage highprecision DTMs, field surveys and rainfall data to study debris flow occurrence factors of Shenmu area, Taiwan, Nat. Hazards Earth Syst. Sci., 12, 3407-3419, doi:10.5194/nhess-12-34072012, 2012.

Occhiena, C., Coviello, V., Arattano, M., Chiarle, M., Morra di Cella, U., Pirulli, M., Pogliotti, P., and Scavia, C.: Analysis of microseismic signals and temperature recordings for rock slope stability investigations in high mountain areas, Nat. Hazards Earth Syst. Sci., 12, 2283-2298, doi:10.5194/nhess-12-22832012, 2012.

Tai, Y. C. and Kuo, C. Y.: Modelling shallow debris flows of the Coulomb-mixture type over temporally varying topography, Nat. Hazards Earth Syst. Sci., 12, 269-280, doi:10.5194/nhess-12269-2012, 2012.

Tsai, M. P., Hsu, Y. C., Li, H. C., Shu, H. M., and Liu, K. F.: Application of simulation technique on debris flow hazard zone delineation: a case study in the Daniao tribe, Eastern Taiwan, Nat. Hazards Earth Syst. Sci., 11, 3053-3062, doi:10.5194/nhess-113053-2011, 2011. 